\title{
Juventude, território e ativismos nas periferias da metrópole:notas sobre uma pesquisa.
}

Youth, territory and activism in the peripheries of the metropolis: notes on a survey

Juventud, territorio y activismos en las periferias de la metrópolis: notas sobre una búsqueda

Jeunesse, territoire et activisme dans les périphéries de la métropole : notes sur un sondage

\section{Artur Sérgio Lopes}

\section{(2) OpenEdition}

\section{Journals}

\section{Edição electrónica}

URL: http://journals.openedition.org/espacoeconomia/3043

DOI: $10.4000 /$ espacoeconomia.3043

ISSN: 2317-7837

Editora

Núcleo de Pesquisa Espaço \& Economia

\section{Refêrencia eletrónica}

Artur Sérgio Lopes, « Juventude, território e ativismos nas periferias da metrópole:notas sobre uma pesquisa. », Espaço e Economia [Online], 11 | 2017, posto online no dia 05 abril 2018, consultado o 01 maio 2019. URL : http://journals.openedition.org/espacoeconomia/3043 ; DOI : 10.4000/ espacoeconomia.3043

Este documento foi criado de forma automática no dia 1 Maio 2019

(C) NUPEE 


\section{Juventude, território e ativismos nas periferias da metrópole:notas sobre uma pesquisa.}

Youth, territory and activism in the peripheries of the metropolis: notes on a survey

Juventud, territorio y activismos en las periferias de la metrópolis: notas sobre una búsqueda

Jeunesse, territoire et activisme dans les périphéries de la métropole : notes sur un sondage

Artur Sérgio Lopes

\section{Introdução}

1 Este artigo busca compreender as tensões entre os princípios e motivações que orientam as ações e práticas em torno do ativismo juvenil, bem como a condição juvenil no qual essas ações e práticas se realizam e se reproduzem. Refere-se, assim, ao jovem que vivencia a sua condição popular, periférica, proletária; o jovem que é ativista, onde sua condição é, em sua grande maioria, objeto de sua ação. O que orienta a investigação é a problemática concernente às mediações em que o ativismo juvenil se insere: mediações da política e do poder.

2 O estudo em andamento privilegia as ações, eventos e mobilizações correspondentes ao ativismo juvenil (e ao campo de articulações sociopolíticas no qual este se inscreve) na Zona Oeste da cidade do Rio de Janeiro, correspondente à Área de Planejamento 5, regiões administrativas de Realengo (XXXIII RA), Bangu (XVII RA), Campo Grande (XVIII RA) e Santa Cruz (XIX RA), mais especificamente os bairros de Bangu e Senador Camará, com destaque para Vila Aliança conjunto habitacional, que junto com o bairro de Senador Camará configura o que se tem definido como Complexo de Camará. Privilegiam-se, também, aproximações com a realidade da Baixada Fluminense, no que se refere à 
trajetória das investigações e vivências do observador, o que permite comparações e análises.

3 Neste trabalho as ações, práticas, mobilizações e eventos do ativismo juvenil em Vila Aliança e Senador Camará serão referenciados, pontualmente, como forma de balizamento para a construção possível de uma Geografia da Ação e da Condição Juvenil. È dada ênfase ao território, em sua correspondência como os conceitos de rede e lugar, cujo exercício se pauta pelo aprendizado destes como categorias analíticas, mas também como categorias normativas, que se fazem presentes no léxico que acompanha as falas e discursos nos eventos, ações e mobilizações destes ativismos.

4 A organização do presente trabalho é composta de três seções, além das considerações finais. A primeira seção diz respeito à relação entre juventude e movimentos sociais, que, de forma breve, explicita as perspectivas de compreensão sobre a emergência da temática juvenil no presente, seus lastros históricos e possibilidades enunciadas a partir da visibilidade do jovem como sujeito. Na segunda, o território, assim como sua correspondência com os conceitos de lugar e rede, são postos em tela, no que se referem: ao debate teórico-conceitual em que essas categorias estão inscritas; à correspondência entre território e poder, assim como às formas de apropriações, subjetivações e representações do sujeito. Na última seção, enseja-se refinar a compreensão do território como prática discursiva inserida no campo ético-político do ativismo juvenil.

\section{Juventude e movimentos sociais - notas prévias.}

O jovem em questão é aquele que milita no ativismo cultural, no movimento estudantil (secundarista e universitário), nas questões concernentes aos direitos humanos, à cidade, às periferias urbanas, ao poder, à violência, nas temáticas relativas ao gênero e ao étnico. Esse jovem se faz representar a partir de formatos sociopolíticos que traduzem identidades e resistências - os coletivos, as ocupações - assumindo feições comportamentais, narrativas, políticas e ideológicas. 0 jovem em questão igualmente experimenta a sua condição, a condição proletária, as condições de existência e o futuro em questão.

Jean Tible, em entrevista concedida à revista Caros Amigos (maio de 2016, edição especial), informa aspectos relevantes para a compreensão da emergência juvenil por via dos novos ativismos. Afirma que tal emergência tem "a ver com a nova geração que é inclusive global" (NABUCO; PRIMI; FIDELIS 2016, p. 26), observa que seus entrevistadores talvez "tenham vivenciado uma nova quebra anterior", que correspondeu "a criação do PT, o Lula, o MST, a CUT, o Movimento Negro, o Movimento Feminista. Mas é interessante observar como todos eles são interpelados pela nova geração". Pauta, assim, a temática dos novos ativismos em suas correspondências com as configurações, redes, políticas e representações em escala global, mas também balizadas pelo geracional, que se desdobra na memória e nos marcos da história recente. Identifica momentos de quebras ao se referenciar aos anos 1980 e às manifestações e mobilizações no presente. Conduz a ideia de continuidade, ainda que com momentos de descontinuidade, períodos de refluxos e saturações, momentos em que o novo é forjado. $O$ que se reforça ao referenciar-se aos anos 1970, 1960, período no qual se observa que determinados debates já se ocorriam (Ibid., p. 27). 
7 As formulações presentes na entrevista concedida por Jean Tidle vão ao encontro das perspectivas analíticas que embasam esse estudo. A juventude compreendida como expressão do urgente e do possível tem pautado a agenda do ativismo social e das articulações civis em torno da implantação de políticas publicas nos últimos anos. O que, por sua vez, se constitui por marcos histórico que vão dar sentido às rupturas e irrupções.

Os levantes de 1968 constituem o ponto de inflexão, onde "a juventude socializada durante a segunda-guerra mundial estava começando a questionar os padrões culturais herdados do passado" (CARDOSO, 2014, p. 11). Configura-se, assim, em desgaste e saturação, anunciando a crise. $O$ que se expressa na efervescência dos idos dos anos 1960, mais especificamente nos levantes políticos de 1968. Levantes de caráter mundial (BADIOU, 2012; HARVEY, 2013;).

9 Os levantes de 1968 pontuaram a crítica ao Estado, à burocracia, ao dogmatismo, ao poder exercido nas escolas, nas fábricas, nas instituições psiquiátricas. Criticas que já se formulavam no imediato pós-Guerra, mas que desembocaram com toda carga de significados nestes Maios de 1968. No que tange à correspondência (direta) entre os levantes de 1968 e a juventude, a inflexão reside no fato de que "a década de 1960 jogaria por terra boa parte da aposta normativa das teorias sobre 'o problema das gerações". 0 que colocou em questão a capacidade das velhas gerações de "transferirem a herança cultural às novas, ou de garantirem a elastrajetórias padronizadas e sempre ascendentes" (CARDOSO, 2014 p. 13).

10 A inflexão põe em pauta considerações referente à reprodução das "relações de produção", conforme observa Lefebvre (1977, p. 225). Também põe em pauta questões concernentes à "mecânica do poder", que passa a ser analisada "a partir das lutas cotidianas e realizadas com aqueles que tinham que se debater nas malhas mais fina da rede de poder" (FOUCAULT, 2005, p. 6).

11 A compreensão em tela indica que os eventos de 1968 ou, para darmos mais abrangência, ocorridos entre os idos dos anos 1960 e início dos anos 1970, vão impactar os anos subsequentes, caracterizando o que Badiou (2012) define como o quarto Maio, em relação e distinção aos outros três maios definidos pelo autor. ${ }^{1}$

Gostaria de sustentar que nenhum desses três componentes [três maios] é mais importante do que o outro, porque houve um quarto Maio de 1968, que foi essencial e ainda determina o futuro. Esse Maio de 1968 é o menos inteligível, porque se manifestou ao longo do tempo, e não naquele instante. Ele foi o que se seguiu ao lindo mês de maio, gerando anos políticos intensos. Dificilmente perceptível, se nos ativermos estritamente às circunstâncias iniciais, ele domina a sequência que vai de 1968 a 1978, depois é reprimido e absorvido pela vitória da união da esquerda e pelos tristes "anos Mitterrand". Fala-se dele como "década de 1968", e não como "Maio de 1968" (BADIOU, 2012, p. 33).

O quarto Maio traduz, assim, "a convicção de que, a partir dos anos 1960, assistimos ao fim da velha concepção política". Traduz, também, "a busca um tanto cega, durante toda a década de 1970-1980, de outra concepção de política" (Ibid. p.33). A ideia-chave aqui é que o quarto maio expressa o processo que desemboca no presente, onde:

A velha concepção com que se tentava romper repousa sobre a ideia dominante (em todas as espécies de militantes), e nesse sentido uniformemente aceita no campo 'revolucionário', de que existe um agente histórico que traz a possibilidade de emancipação. Esse agente histórico é chamado de classe operária, proletário e, algumas vezes povo. Sua composição e sua extensão são discutidas, mas sua existência é aceita. Essa convicção partilhada de que existe um agente 'objetivo', 
inserido na realidade social, que traz a possibilidade de emancipação é talvez a maior diferença entre aquela época e a atual. Entre as duas: os sinistros anos 1980 (ibid.). processos e dinâmicas correspondentes às ações, políticas e ativismos em torno da juventude. O território, também nessa perspectiva, permite decompor aspectos significativos da vida e o vivido nas favelas, conjuntos habitacionais, loteamentos 
populares. É possível afirmar que o território é assim como o lugar e a rede, categorias explicativas de uma geografia da condição e do ativismo juvenil.

Essa geografia nos permite apreender as correspondências entre espaço e política, espaço e cultura, espaço e economia. O espaço, assim, assume a sua primazia como conceito e categoria na geografia, conforme sugere Santos (1997). Por sua vez, toma-se aqui como referência, o espaço no sentido atribuído por Lefebvre (2008; 1977). O espaço que é produto e ao mesmo tempo incide sobre a reprodução das relações sociais de produção, onde todo o espaço se torna lugar da reprodução.

Essa reprodução se realiza através de um esquema relativo à sociedade existente, cujo caráter essencial é ser conjunta - disjunta, dissociada, mantendo uma unidade, a do poder, na fragmentação. Esse espaço hegemônico - fraturado não é somente o espaço global do planejamento ou o espaço parcelar do arquiteto e dos promotores imobiliários, é também o espaço das obras de arte, por exemplo, o do mobiliário e do design. É o estetismo que unifica os fragmentos funcionais de um espaço deslocado realizando, assim, seu caráter homogêneo e fraturado.

[...] É o espaço onde a conexão coercitiva se efetua por meio de um sistema de acesso às partes deslocadas: o espaço, ao mesmo tempo uniforme e duramente constrangedor das periferias e dos subúrbios; onde os cortiços, as favelas, as cidades de urgência completam os subúrbios residenciais onde as normas reinam, prescrevendo as utilizações do tempo, enquanto se devota ao espaço toda espécie de discursos,interpretações, ideologias e valores "culturais", artísticos, etc. (LEFEBVRE, 2008, p. 49)

O espaço, nesses termos, incide sobre os poderes, as normas, as representações, as simulações, os discursos, as ideologias; incide sobre as separações, as segregações, as ausências; sobre o cotidiano, o tempo, a mobilidade, os usos. 0 espaço é entendido também, na compreensão de Rogério Haesbaert (2014):

O espaço geográfico, na verdade, partindo de uma posição relacional, envolve, como queira Milton Santos, tanto o universo dos objetos quanto dos sujeitos e suas ações, tanto a dimensão dos elementos (aparentemente) fixos quanto móveis, tanto a dimensão material quanto a dimensão imaterial. Na expressão de Henri Lefebvre, "o conceito de espaço denota e conota todos os espaços possíveis, abstratos ou 'reais', mentais e sociais. Entre outros, ele contém estes dois aspectos: o espaço de representação - a representação do espaço" (1986: 345; tradução livre). Nesse sentido, todo espaço geográfico é também ação, movimento e representação simbólica (2104, p. 37)

21 A compreensão que se desenvolve para esse estudo situa o território em seus nexos com o espaço, com a produção do espaço em suas imbricações. O território - assim como a rede, o lugar, para ficarmos nesse conjunto de categorias - permite apreender aspectos, nuanças, tensões presentes nas dinâmicas de produção do espaço. Configura, assim, no que se refere ao tratamento específico dessas categorias nessa investigação, algo muito próximo do que Haesbaert (2014) delineia como uma constelação de conceitos. Não se pretende aqui traçar a trajetória desses conceitos em relação à história do pensamento geográfico, mas de explicitar o entendimento de que o tratamento diante do território, nas bases em que se constitui essa pesquisa, conduz as correspondências entre lugar e território, rede e território.

Faz-se necessário situar, previamente, a compreensão sobre os nexos entre ativismo juvenil, cotidiano e poder. Refere-se, assim, numa primeira aproximação, aos nexos globais que incidem sobre o ativismo juvenil no que tange às relações de poder. Nesse sentido o poder assume a sua primazia como componente analítico, e que se expressa em sua tensão na política, na ação em sua correspondência com o cotidiano. A verticalidade do 
poder se coloca por via do acirramento das relações de poder no espectro do que WACQUANT define como "Estado-penitência", em substituição do Estado-previdência. (2011). Isso se reproduz na dimensão do cotidiano, com suas especificidades e capilaridades, nos "pequenos enfrentamentos", nas "microlutas", nas "pequenas relações de poder", como nos informa Michel Foucault (2015, p. 226).

Nesse sentido a verticalidade do poder articula escalas e feições reticulares. Revela, assim, redes de poder. A rede assume aqui seu lugar analítico, pelo fato de ser conforme indica Santos (1997, p. 222), "global e local, uma e múltipla, estável e dinâmica", o que também é indicado por Dias $(2005$, p. 23). A rede comporta, assim, a instantaneidade e a simultaneidade.A rede em sua correspondência como o território, delineia o que Haesbaert(2004, p. 301) define como território-rede, onde de "alguma forma, territorializar-se, hoje, a ação de controlar fluxos, de estabelecer e comandar redes". As redes "jamais são completamente desmaterializadas", de uma forma ou de outra, estão sempre "desenhando materialmente territórios".

A rede, assim como sua correspondência com o território, interessa a esta pesquisa no que diz respeito ao rebatimento das escalas globais no urbano-metropolitano em suas expressões periféricas. Remete, assim, à vida da cidade, mas também à vida de bairro (MARTINS, 2008; SEABRA, 2004). É nas relações, nexos e tensões que se configuram historicamente entre o bairro e a cidade, o bairro e a metrópole que situamos a realização em suas contradições da ação social e do ativismo juvenil, muito embora essas ações estejam intrinsecamente ligadas aos processos em escala global, que por isso, remetem a uma historicidade. A escala do bairro, das centralidades locais, em seus vínculos com a dinâmica metropolitana é onde se privilegia não apenas a rede em sua correspondência como território, mas o lugar, também em sua correspondência com o território, e este como expressão do poder.

25 Aqui se situam as redes do narcotráfico, a partir do que Sousa $(2000 ; 1997)$ define como fragmentação do tecido sociopolítico-espacial. A fragmentação simboliza, assim, "um processo de solapamento da cidadania que, conquanto incorpore também uma dimensão de 'luta de classes', não admite ser reduzido a ela" (1997, p. 256). Essa fragmentação se constitui por dois processos:

[...] enquanto as favelas vão "se fechando" sob o impacto do narcotráfico, os condomínios exclusivos (ou fechados) representam o ápice da auto-segregação. Uns citadinos, tradicionalmente privados do exercício da cidadania, são agora cada vez mais submetidos à tirania do tráfico; outros, escapistas, buscam proteção em 'cidadelas' como condomínios e shopping centers. Entre os territórios diretos do tráfico e as cidadelas da auto-segregação restam os espaços que, por sua superfície e número de habitantes, formam a maior parte da cidade, as "áreas neutras", onde a população está particularmente exposta à violência da "guerra civil molecular" (Ibid., p. 257).

Algumas considerações, ainda que preliminares, fazem-se necessárias e se referem ao hiato temporal que a citação acima comporta em relação ao presente. É possível afirmar, sem medo de erro que as "áreas neutras" não são tão neutras mais. É possível afirmar, que cada vez mais se enseja uma sociabilidade constituída pelas "dobras do legal-extralegal", que configuram as relações de poder, e pelas "bordas do formal-informal" que configuram os circuitos da economia (TELLES, 2010). As incidências das relações de poder sobre o espaço cada vez mais impõem a compreensão de dinâmicas de poder a partir da fluidez na distinção entre o legal e o extralegal. Fluidez que extrapola a escala do lugar e do vivido e se revela em suas conexões globais. Fluidez que se constituí na 
correspondência com o tradicional, o hábito, o cotidiano nos bairros, favelas e conjuntos habitacionais.

Em Vila Aliança, na área de maior de maior controle territorial do narcotráfico observa-se as barreiras nas vias públicas, como forma de controlar o acesso. Também podemos observar os jovens recrutados pelo tráfico, nas motocicletas e com seus AR 15. Por fim, observa-se que os muros são grafitados com imagens e mensagens bíblicas. Tais grafites, de qualidade profissional, foram financiados pelo narcotráfico, já que os narcotraficantes são, em sua maioria, evangélicos. Em outro bairro, também na zona oeste do Rio de Janeiro, identifica-se a mesma pratica, porém sob o comando da milícia local. Tais exemplos informam a conexão entre os poderes em sua dimensão extralegal com as expressões da vida civil-comunitária nessas periferias - são poderes que de certa forma configuram pactos territoriais e, nem por isso menos déspota.

Ao buscarmos apreender o poder nessa escala, a relação lugar-território, apresenta-se como ferramenta analítica. Referencia-se aqui a definição em Carlos (1996), onde o "lugar se produz na articulação contraditória entre o mundial que se anuncia e a especificidade histórica do particular". O lugar se apresentaria, assim, "como ponto de articulação entre a mundialidade em constituição e o local enquanto especificidade, enquanto momento" (Ibid., p. 15-16). Atribui-se,assim uma dimensão representativa à história particular. $O$ sujeito, dessa forma, constitui-se como expressão da própria história local. Vale, aqui, remetermos a Martins ${ }^{2}$ (Apud. Carlos 1996p. 25-26), no qual para este

a história local é a história da particularidade embora se determine pelos componentes universais da história. Isto é, embora na escala local raramente sejam visíveis as formas e conteúdos dos grandes processos históricos, ele ganha sentido por meio deles quase sempre ocultos e invisíveis [...] é no âmbito do local que a história é vivida e é onde, pois, tem sentido.

O lugar apreendido nessas referências informa aspectos expressivos para a investigação em andamento. O sentido histórico e de mediação atribuído ao lugar possibilita compreender os processos que configuraram essas mediações. Processos correspondentes às relações de poder, que se traduzem nas formas de dominação no território em sua escala próxima da vida cotidiana. Traduzem-se também na noção de tradição de distinção e diferenciação. Os estabelecidos e os outsiders na abordagem de Elias e Scotson (2000); as distinções presentes nas badaladas dos sinos durante o cortejo fúnebre (MARTINS, 2008, p. 102-118). Ambos os exemplos remetem ao urbano na cidade sob o capitalismo concorrencial, ao subúrbio que precede, e cria as bases territoriais, para o processo de metropolização. Tais distinções e diferenciações se fazem presente hoje, de forma mais fragmentada e submetidas a poderes mais complexos. Vai-se ao encontro com leituras críticas à noção de lugar sob enfoque nostálgico, marcado por elementos de dualidades, como exemplo os não-lugares em Augé (2008). Aspecto observado por Souza (2013, p. 111-134), que atualiza o debate, sinalizando a compreensão sobre a correspondência entre escala e lugar.

Ao conceber as conexões entre lugar e território, privilegiando como escala de análise as periferias urbanas (através dos loteamentos, conjuntos habitacionais, favelas, mas também através dos contextos sócio-espaciais em que formas se localizam e se articulam, articulando fragmentos da cidade), pontuamos a perspectiva de compreensão dá o sentido do pertencimento - comum nas falas dos militantes e ativistas - com as expressões do poder e do que este carrega como constrangimento. Porém o território, nessa mesma escala, expressa a tensão entre dominação e apropriação. Aspecto levantado por 
Haesbaert (2004) ao fazer referências às formulações contidas em Lefebvre (1986). A dominação se refere à técnica, ao poder; a apropriação ao uso, onde de acordo com Lefebvre:

0 uso reaparece em acentuado conflito com a troca no espaço, pois ele implica "apropriação" e não "propriedade". Ora, a própria apropriação implica tempo e tempos, um ritmo ou ritmos, símbolos e uma prática. Tanto mais o espaço é funcionalizado, tanto mais ele é dominado pelos "agentes" que o manipulam tornado-ounifuncional, menos ele se presta à apropriação. Por quê? Porque ele se coloca dentro do tempo vivido, aquele dos usuários, tempo diverso e complexo. (LEFEBVRE, 1986 [La Production de l' Espace], p.411-412, destaque do autor, apud HAESBAERT, op. cit. p. 95).

31 É na tensão inerente a esses componentes que o território se apresenta, não apenas como categoria analítica, mas também como expressão da prática, da ação, das narrativas e representações presentes no ativismo juvenil. 0 território é termo da moda não isento de problemas, incompletudes...

\section{Território, mediações e narrativas.}

Vainer (2013, pp. 35-36) indica que os anos 1990 foram a década que se configurou a "ruralização da luta social",

Se no processo de democratização dos anos 1980 os movimentos operários e urbanos pareciam traduzir politicamente as contradições da modernização acelerada no qual havia passado nossa sociedade nos trinta anos anteriores, o período que se abriu nos anos 1990 apontou para uma espécie de "ruralização da luta social". O Movimento de Trabalhadores Rurais Sem Terra (MST), o Movimento de Atingidos por Barragens (MAB) e a resistência de populações tradicionais à destruição de seus meios e modos de vida ocuparam o proscênio da arena política.

É possível afirmar que os anos 2010, são os anos da juvenilização da luta social: o que o autor supracitado indica. É claro que assertivas como essas correm o risco da generalização, mas estão corretas por indicarem o que baliza esses períodos, que se distingue, embora também haja vínculos, links entre si, nem sempre visíveis. Identificar esses vínculos é um exercício que, muito embora não constitua o escopo da pesquisa, informa aproximações necessárias. É nessa perspectiva que o território é compreendido nesse estudo além do seu caráter analítico. A pergunta necessária: por que o território se faz tão presente nas falas sobre a juventude e o ativismo juvenil? Não se trata de afirmar o território como a novidade do momento. Nas falas e textos sobre os movimentos rurais, o território se fazia presente, com outros sentidos (uma sociabilidade marcada pelo vínculo com a terra e o território; os assentamentos rurais como expressão da territorialização do movimento rural), mas se fazia presente (FERNANDES, 1999).

É possível informar que o território concebido como categoria analítica nos permite apreender o território como narrativa. Entendendo que "o discurso é efeito de sentidos entre locutores" (ORLANDI, 2012. p. 20), o que se busca aqui é apontar, de forma sucinta, componentes que nos permita compreender os significados atribuídos ao território nessas narrativas.

É necessário observar que o território reconhecido como termo usado nas narrativas sobre e dos ativismos juvenis constitui-se como uma feição distinta da que lhe atribuída como categoria analítica. Para tal entendimento busca-se compreender a natureza das distinções que se opera. Haesbaert (2014, p. 31) esclarece: 
Ainda que reconheçamos três modalidades de categorias ou conceitos - analíticas, da prática e normativas, estamos cientes também da sua indissociabilidade. Enquanto uma categoria analítica é, um instrumento no processo de investigação do pesquisador - ou um conceito no seu sentido mais difundido, a categoria da prática é um "conceito" - ou noção - do senso comum, utilizado nas práticas cotidianas do discurso ordinário, e a categoria normativa tem como objetivo primeiro indicar um caminho, tem um caráter mais propositivo do que analítico, como nos conceitos de região e território utilizados pelo Estado enquanto agente planejador. ativistas, parece se constituir como uma categoria normativa, que se faz presente nas praticas vivenciadas por esses ativismos. É perceptível que esta assertiva não caracteriza uma cisão entre essas categorias, como observa Haesbaert, "o pesquisador ou o intelectual não pode prescindir do conhecimento de suas categorias de análise enquanto utilizadas (e recriadas) também nas ações do sendo comum..." (Ibid.). É expressiva a presença de estudantes universitários, professores e pesquisadores militantes nas ações, projetos, atos e eventos que compõem as práticas do ativismo. 0 que distingue não é o oficio do militante (considerando que não é pelo ofício que eles militam, mas pela identidade e condição que se fazem representar na militância), mas sim o lugar estratégico que a narrativa comporta. encobrem as estratégias, enquadramentos presentes nas falas globais sobre a juventude: as "comunidades epistêmicas internacionais", da qual nos fala Furiati (2010); estratégias, enquadramentos e capturas que são apreendidos na pesquisa através da análise sobre a emergência, deslocamento e reelaboração do campo discursivo que expressa a dinâmica política da questão social, do sujeito, dos movimentos e ações sociais nos últimos quarenta anos. Termos como autonomia, empoderamento, coletivo, base, território, rede, gênero, raça, classe, etc, compõem o léxico e seus significados, nas ações e estratégias dos movimentos e ativismos sociais neste período. Alguns perdem sua proeminência e primazia, enquanto outros emergem. Existe ainda aqueles que ganham novos significados, que remetem a conjunturas e momentos.

As inquietações que motivam a investigação sinalizam para a hipótese de que os léxicos que compõem o campo discursivo (BOURDIEU, 1998) no qual o ativismo juvenil se inscreve constitui-se num cenário de deslocamentos, ambivalência e capturas. Capturas que se constituem como derivação da captura da subjetividade, como nos informa Alves (2011) e que se expressa na derivação do político, das formas de representação e de enunciação do sujeito.

O trato analítico, assim, indica que é pela compreensão desse campo que identificamos umas das facetas da captura, no que se refere à vinculação desse campo com as esferas globais e estruturantes do fazer política. O que importa reter no momento é o desdobramento das formas cotidianas desse fazer política. Trata-se do que é basilar neste estudo: a captura expressa como tensão nas mediações que compõe a ação.

O território como expressão que referência as noções de autonomia, identidade e pertencimento, pautadas pelos recortes do étnico, do gênero, da cultura e do próprio território (a favela e a periferia reconhecidas como lugar da fala), se constituí nesse campo de tensão, no qual a captura é experimentada, mas também há o que escapa, o que resiste. 


\section{Considerações sobre o possível}

41 A correspondência (seus limites e tensões) entre a condição juvenil e o possível delineia o campo de mediações que a ação ativista pressupõe. Ação que se realiza a partir do localizar-se no mundo como componente necessário para a reprodução dos movimentos de resistência. Ação esta que, ao expressar e tornar visível as urgências destes jovens conduz a perspectiva da afirmação das identidades destes num contexto marcado por ausências, pela segregação e subordinação. Trata-se, assim, da possibilidade do encontro em tempos de desencontro. Nesse sentido é que o território, como categoria normativa se expressa. 0 território como narrativa é a expressão do possível.

Pensar as possibilidades é pensar o possível "mediado pela consciência social crítica, pelo conhecimento crítico - pela crítica que revê continuamente certezas e verdades, suas condições, suas limitações, seus bloqueios, sobretudo os bloqueios do que crêem isentos de limites de compreensão" (MARTINS 2003, p. 12). o possível, nestes termos, pressupõe escolhas, caminhos a percorrer. Conforme informa Henri Lefebvre (1979, p. 41), não “ existe atividade sem projeto; ato sem programa, práxis política sem exploração do possível e do futuro".

\section{BIBLIOGRAFIA}

Livro/Book:

ALVES, Giovanni. Trabalho e subjetividade: o espirito do toyotismo na era do capitalismo manipulatório. São Paulo: Boitempo, 2011.163p.

ANTUNES, Ricardo. Os Sentidos do trabalho. Ensaio sobre a afirmação e a negação do trabalho. São Paulo: Boitempo, 2009. 287p.

AUGÉ, Marc. Não-Lugares: Introdução a uma antropologia da supermodernidade. Campinas: Papirus editora, 2008. 111p.

BADIOU, Alain. A Hipótese comunista. São Paulo: Boitempo Editorial, 2012. 150p.

CARLOS, Ana Fani Alessandri. O lugar no/do mundo. São Paulo, Hucitec, 1996. 150p.

ELIAS, Nobert e SCOTSON, John L. Os Estabelecidos e os Outsiders - Sociologia das Relações de Poder a partir de uma Pequena Comunidade. Rio de Janeiro, Jorge Zahar Editor, 2000. 224p.

FERNANDES, Bernardo Mançano. MST. Movimento dos trabalhadores rurais sem terra: formação e territorialização em São Paulo. São Paulo: Hucitec, 1999. 285p.

FOUCAULT, M. Microfísica do Poder. Rio de Janeiro, Graal: 2005. 295p.

HAESBAERT, Rogério. O Mito da Desterritorialização. Do "Fim dos Territórios" à

Multiterritorialidade. Rio de Janeiro: Betrand Brasil, 2004. 395p. 
Viver no limite: território e multi/transterritorialidade em tempos de in-segurança e contenção. Rio de Janeiro: Betrand Brasil, 2014. 319p.

HARVEY, David. Condições Pós-Modernas. São Paulo, Edições Loyola,1996. 349p.

O Novo Imperialismo. São Paulo: Edições Loyola, 2005. 201p.

O Neoliberalismo: história e implicações. São Paulo: Edições Loyola, 2013. 252p.

LEFEBVRE, Henri. Sociologia de Marx. Rio de Janeiro: Editora Forense-Universitária, 1979. 141p.

Espaço e política. Belo Horizonte: Editora UFMG, 2008. 190p.

MARTINS, Jose de Souza. A sociedade vista do abismo: novos estudos sobre exclusão, pobreza e classes sociais. Petrópolis: Editora Vozes, 2003. 228p.

A aparição do demônio na fábrica: origens sociais do Eu dividido no subúrbio operário. São Paulo: Ed. 34, 2008. 224p.

MÉSZÁROS, István. Para Além do Capital. Rumo a uma teoria da transição. São Paulo: Boitempo Editorial, 2012.1102p.

ORLANDI, Eni Puccinelli. Análise de discurso: princípios e procedimentos. Campinas: Pontes editora, 2012. 100p.

SANTOS, Milton. A Natureza do Espaço. São Paulo, Hucitec, 1997. 308p.

SOUZA, Marcelo Lopes de. 0 desafio metropolitano: um estudo sobre a problemática sócioespacial nas metrópoles brasileiras. Rio de Janeiro: Bertrand Brasil, 2000. 368p.

Os conceitos fundamentais da pesquisa sócio-espacial. Rio de Janeiro: Bertrand Brasil, 2013.320p.

TELLES, Vera da Silva. A cidade nas fronteiras do legal e ilegal. São Paulo: Argumentum, 2010. 216p.

WACQUANT, Loïc. As prisões da miséria. Rio de Janeiro: Zahar, 2011. 2017p.

Capítulo de Livro/ Book chapter:

CARDOSO, Adalberto. Introdução: Juventudes, gerações e a atualidade de um tema clássico. In: CARDOSO, Adalberto (org.). Juventudes e desigualdades. Rio de Janeiro: Azougue Editorial, 2014. p. 5-45.

DIAS, Leila Cristina. Os Sentidos da Rede: Notas para Discussão. In: DIAS, Leila Cristina; SILVEIRA, Rogério Leandro Lima da (Org.). Redes, Sociedades e Territórios. Santa Cruz do Sul: EDUNISC, 2005.p. 11-28.

LEFEBVRE, Henri. A irrupção: de Nantarre ao auge. In: LEFEBVRE, Henri (org.). A Irrupção. A revolta dos jovens na sociedade industrial: causas e efeitos. São Paulo: Editora Documentos, 1968. p. 72-169.

Estrutura Social: a reprodução das relações sociais. In FORACCHI, Maralice Mencarini;

MARTINS, José de Souza (org): Sociologia e Sociedade (leituras de introdução à Sociologia). Rio de Janeiro: Livros Técnicos e Científicos, 1977. p. 219-252.

SEABRA, Odette Carvalho de Lima. São Paulo: a cidade, os bairros e a periferia. In: CARLOS, Ana Fani Alessandri; OLIVEIRA, Ariovaldo Umbelino (org.). Geografias de São Paulo: Representação e crise da Metrópole. São Paulo: Contexto, 2004.p. 271-311) 
SOUZA, Marcelo Lopes de. Exclusão Social, Fragmentação do Tecido Sociopolítico-Espacial da Cidade e "Ingovernabilidade Urbana". In: SILVA, José Borzacchiello da; COSTA, Maria Clelia Lustosa; DANTAS, Eustógio Wanderley Correia (org.). A Cidade e o Urbano - Temas para Debate. Fortaleza, EUFC,1997.p. 247-264.

VAINER, Carlos. Quando a cidade vai as ruas. IN: MARICATO, Ermínia... [et al.]. Cidades Rebeldes: Passe Livre e as manifestações que tomaram as ruas do Brasil. São Paulo; Boitempo/Carta Capital, 2013.p. 35-40.

Periódico/Journal:

LEFEBVRE, Henri. Da teoria das crises à teoria das catástrofes. GEOUSP. Espaço e Tempo. São Paulo, n. 25, 2009. p.138-152.

NABUCO, Aracy; PRIMI, Lilian; FIDELES, Nina. Novos Rumos: entrevista Jean Tible. Caros Amigos (edição especial). São Paulo, maio 2016, p. 26-29.

NOVAES, Regina. As juventudes e a luta por direitos. Le Monde Diplomatique Brasil, São Paulo, novembro, 2012.p. 10-11.

PEREGRINO, Mônica. Juventude, trabalho e escola: elementos para análise de uma posição social fecunda. Cad. Cedes, Campinas, vol. 31, n. 84, 2011, p. 275-291.

Tese, dissertação e monografia/Thesis, dissertation and monograph:

FURIATI, Nídia Maria de Ávila. Juventude e Estado no Brasil. A lógica constitutiva do Conselho Nacional da Juventude no governo Lula, 2010. 356 f. Tese (Doutorado em Sociologia) Departamento de Sociologia, Universidade de Brasília (UNB), Brasília, 2010.

\section{NOTAS}

1. O primeiro Maio de 1968, para Badiou, foi "uma rebelião, uma revolta da juventude universitária e secundarista. Esse é o aspecto mais espetacular, mais conhecido; foi o que deixou imagens fortes, que revimos nesses últimos tempos: manifestações em massa, barricadas, confrontos com a polícia et." (ibid. p. 30). O segundo Maio foi "a maior greve geral de toda história francesa" com uma presença significativa da juventude operária: existe nesse maio "operário um elemento de revolta que é ele também interno a juventude" (ibid. p. 31). O terceiro Maio de 1968 se refere ao Maio libertário. "Diz respeito á questão da mudança dos costumes, das novas relações amorosas, da liberdade individual, à questão que leva ao movimento das mulheres e, mais tarde, dos direitos e da emancipação dos homossexuais" (ibid. p. 32).

2. Martins, José de Souza. Memória, Eletropaulo (Departamento Histórico), julho/dezembro, 1993. São Paulo. 


\section{RESUMOS}

Este trabalho busca compreender as tensões entre os princípios e as motivações que orientam as ações e práticas em torno do ativismo juvenil, bem como a condição juvenil no qual essas ações e práticas se realizam e se reproduzem. Refere-se ao jovem que vivencia a sua condição popular, periférica, proletária; o jovem que é ativista, onde sua condição é, em sua grande maioria, objeto de sua ação. O que orienta a análise é a problemática concernente às mediações em que o ativismo juvenil se insere: mediações da política e do poder.

Understanding tensions between principles and motivations that guide actions and practices concerning youth activism as well as conditions in which these actions and practices take place is this paper's purpose. It concentrates in peripheral, proletarian young people who are activists, which implies that their condition is object of their own activism. The analysis is guided by the problems concerning mediations of youth activism: politics and power.

Este trabajo busca comprender las tensiones entre los principios y las motivaciones que orientan las acciones y prácticas en torno al activismo juvenil, así como la condición juvenil en la cual esas acciones y prácticas se realizan y se reproducen. Para este caso, se hace referencia al joven de condición popular, periférica, proletaria; el joven que es activista, cuya condición es, prioritariamente el objeto de su acción. Lo que orienta el análisis es la problemática concerniente a las mediaciones en que el activismo juvenil se inserta: mediaciones de la política y el poder.

Cette communication vise à comprendre les tensions entre les principes et les motivations qui guident les actions et pratiques autour de l'activisme des jeunes, ainsi que la condition juvénile dans laquelle ces actions et pratiques sont menées et reproduites. Il s'aggit du jeune qui vit sa condition populaire, périphérique et prolétarienne; le jeune militant, dont la condition est, pour la plupart, l'objet de son action. Ce qui guide l'analyse, c'est la problématique concernant les médiations dans lesquelles s'insère l'activisme des jeunes: des médiations de la politique et du pouvoir.

\section{ÍNDICE}

Mots-clés: jeunesse activisme. territoire. périphérie.

Keywords: youth, activism; territory; periphery.

Palabras claves: Juventud, activismo, territorio, periferia.

Palavras-chave: juventude. ativismos. território. periferia.

\section{AUTOR}

\section{ARTUR SÉRGIO LOPES}

Universidade do Estado do Rio de Janeiro. Programa de Pós-Graduação em Políticas Públicas e Formação Humana. UER/PPFH 
E-mail.: rutraoigres@yahoo.com.br 